\title{
How does lymph node yield affect survival outcomes of stage I and II colon cancer?
}

\author{
Chi Chung Foo ${ }^{*^{*}}$ (D) Clement Ku', Rockson Wei ${ }^{2}$, Jeremy Yip ${ }^{2}$, Julian Tsang ${ }^{2}$, Toi Yin Chan², Oswens Lo ${ }^{2}$ and \\ Wai Lun Law ${ }^{1}$
}

\begin{abstract}
Background: According to the American Joint Committee on Cancer staging for cancer of the colon, a minimum of 12 lymph nodes (LN) has to be sampled for accurate staging. This has bearing on the long-term prognosis and the need for adjuvant chemotherapy. The aim of this study was to revisit the association of lymph node yield and the long-term survival in patients with stages I and II, i.e. node-negative, colon cancer.

Method: Consecutive patients who underwent elective or emergency curative resections for cancer of colon between the years 2003 and 2012 were retrospectively reviewed. Only patients with stage I or II diseases (AJCC 8th edition) were included. They were analysed in three groups, LN $<12, \mathrm{LN12}-19$ and LN $\geq 20$. Their clinic-pathological characteristics were compared. The disease-free (DFS) and overall survival (OS) were estimated with the KaplanMeier method and compared with the log-rank test.

Results: There was a total of 659 patients included in the analysis. Twelve or more $L N$ were found in $65.6 \%$ of the specimens. The mean follow-up was 83.9 months. LN $\geq 20$ had significantly better DFS $(p=0.015)$ and OS $(p=0.036)$, whereas $L N<12$ had similar DFS and OS when compared to LN12-19. The advantage in DFS and OS were mainly seen in those with stage II diseases. A lymph node yield of greater than 20 was one of the predictors of favourable DFS, hazard ratio $0.358 ; 95 \% \mathrm{Cl} 0.170-.756, p=0.007$.

Conclusion: The lymph node yield had a significant association with survival outcomes. A lymph node yield of 20 or more was associated with better survival outcomes. On the other hand, lymph node yield less than 12 was not shown to have inferior survival outcomes when compared to those between 12 and 19.
\end{abstract}

Keywords: Lymph node, Colon cancer, Survival

\section{Background}

Staging is an integral part of colon cancer treatment. The widely adopted staging system, TNM staging maintained by the American Joint Committee on Cancer (AJCC) and the International Union for Cancer Control (UICC), requires at least 12 lymph nodes to be harvested for adequate staging [1]. The minimum number of 12 was proposed in the early 1990s and was based on a study that suggested this was enough to determine node positivity in $94 \%$ of the specimens [2]. However, the discussion went on as to what should be the optimal lymph node yield [3]. Studies also suggested that lymph node yield might serve as a prognostic indicator $[4,5]$.

\footnotetext{
* Correspondence: ccfoo@hku.hk

${ }^{1}$ Department of Surgery, University of Hong Kong, Hong Kong, China

Full list of author information is available at the end of the article
}

The technique of complete mesocolic excision, which involves the removal of the mesocolon in its intact envelope and the ligation of the central vascular pedicle, yet again draws the attention of lymph node clearance in colon cancer surgery [6]. This study aimed to revisit the association of lymph node yield and the long-term survival in patients with stages I and II, i.e. nodenegative, colon cancer. The hypothesis of this study was that inadequate lymph node yield would have an adverse effect on survival outcomes and that lymph node yield more than the suggested 12 lymph nodes would have similar survival outcomes.

\section{Method}

This was a retrospective study of consecutive patients who underwent colonic resection of curative intent for 
adenocarcinoma of colon in an academic hospital within the study period from the year 2003 to 2012. Patient demographics, operative information and pathology data were kept in a prospectively maintained database. Those who had stage I or stage II disease were included in the analysis. This study was approved by the institutional review board.

During the study period, routine central vascular pedicle ligation was not practised in right colectomies. For left-sided resections involving the ligation of the inferior mesenteric artery, high ligation was routinely performed unless the surgeon deemed inappropriate. When there were less than 12 lymph nodes sampled, the pathologist would be asked to re-examine the specimen for more.

Patients were followed up every 3 months in the first 2 years, every 4 to 6 months from the third to the fifth year and then yearly thereafter. Clinical examination was performed and the carcino-embryonic antigen level was checked during follow-up visits. Contrast-enhanced computed tomography of the thorax, abdomen and pelvis was performed yearly during the first 3 years and when indicated thereafter. Patients who were operated for colon cancer were routinely followed until death. The survival status of patients was traced from the public hospital central electronic health system, as the death of patients within the territory would be registered in the system regardless of cause and place of death. Follow-up time and time to recurrence or death were counted from the date of operation.

Patients were analysed according to the number of lymph nodes harvested from the specimen. They were divided into three groups, < 12 (LN<12), 12 to 19 (LN12-19) and $\geq 20(\mathrm{LN} \geq 20)$. Twenty was chosen as the cut off as a previous study showed no significant survival benefit beyond this number [7]. The difference between these groups was analysed with the $\chi^{2}$ test for categorical variables and the one-way analysis of variance (ANOVA) test for continuous variables. Survival analysis was done with the Kaplan-Meier estimate method. The overall (OS) and disease-free survival (DFS) of these groups were compared with the log-rank test. Univariate analysis of various clinic-pathological parameters using the survival outcomes as the dependent factor was performed with the CoxMantel log-rank test. A hazard ratio of greater than 1 signifies poorer survival outcomes. Significant parameters, those with $p$ value $<0.05$, were included in the multivariate analysis using the Cox regression analysis in a backward stepwise method. All statistical calculations were performed with the SPSS version 23 (IBM, USA).

\section{Results}

\section{Patient cohort}

There was a total of 659 patients included in this study, with $23.7 \%$ and $76.3 \%$ having stage I and stage II disease, respectively. The number of lymph nodes harvested ranged from 0 to 86, with a mean of 15.2. There were 12 or more lymph nodes in $65.6 \%$ of the specimens. The mean followup was 83.9 months. There were 89 (13.5\%) patients who suffered from disease recurrence. Table 1 summarized the demographic characteristics of this study cohort.

\section{Lymph node yield}

The clinic-pathological parameters of the three lymph node yield groups were shown in Table 1 . Female gender $(p=0.034)$, younger age $(p<0.001)$, ASA 1 and $2(p=$ $0.002)$, laparoscopic surgery $(p=0.011), \mathrm{T} 3$ and $\mathrm{T} 4$ tumours $(p=0.005)$, negative lymphovascular permeation $(p=0.049)$, greater tumour size $(p<0.001)$ and those that were operated from 2008 to $2012(p<0.001)$ were associated with a higher lymph node yield.

\section{Disease-free survival}

The DFS according to the lymph node yield was shown in Fig. 1 a. $L N \geq 20$ had significantly better DFS $(p=0.015)$ compared to the other two groups. Figure $1 \mathrm{~b}$ and $\mathrm{c}$ showed the DFS of stage I and II diseases, respectively. The survival benefit from a higher lymph node yield was mainly seen in patients with stage II diseases. The 5-year DFS was $86.2 \%$, 82.7\% and $91.0 \%$ for $\mathrm{LN}<12$, $\mathrm{LN} 12-19$ and $\mathrm{LN} \geq 20$, respectively (Table 2 ). The 10 -year DFS was $84.0 \%, 81.6 \%$ and 91.0\% for $\mathrm{LN}<12$, $\mathrm{LN} 12-19$ and $\mathrm{LN} \geq 20$, respectively.

The association between various clinic-pathological parameters and the DFS were shown in Table 3. Among these, lymph node yield greater than 20 (HR 0.358; 95\% CI 0.170-.756, $p=0.007$ ), obstructed tumour (HR 2.061; 95\% CI 1.128-3.767, $p=0.019)$, high preoperative CEA level (HR 1.004; 95\% CI 1.000-1.008, $p=0.038$ ), poorly differentiated tumour (HR 2.263; 95\% CI 1.058-4.843, $p=0.035)$ and $\mathrm{T}$ stage $\geq 3$ (HR 17.216; 95\% CI 2.367$125.235, p=0.005)$ were predictors of disease-free survival from the multivariate analysis.

\section{Overall survival}

The OS according to the lymph node yield was shown in Fig. 2 a. $L N \geq 20$ lymph nodes had significantly better OS $(p=0.036)$. Figure $2 \mathrm{~b}$ and $\mathrm{c}$ showed the OS of stage I and II diseases, respectively. Similar to the DFS, the survival benefit from a higher lymph node yield was mainly seen in those with stage II diseases. The 5-year OS was $68.2 \%, 70.4 \%$ and $78.9 \%$ for $\mathrm{LN}<12$, LN12-19 and $\mathrm{LN} \geq 20$, respectively (Table 2 ). The 10 -year OS was $44.8 \%, 51.2 \%$ and $57.5 \%$ for $\mathrm{LN}<12, \mathrm{LN} 12-19$ and $\mathrm{LN} \geq 20$, respectively.

The independent predictors of OS were high preoperative CEA level (HR 1.005; 95\% CI 1.002-1.008, $p<$ 0.001 ) lymphovascular permeation (HR 1.580; $95 \% \mathrm{CI}$ $1.110-2.250, p=0.011)$, ASA $\geq 3$ (HR 1.907; 95\% CI $1.443-2.521, p<0.001$ ), male gender (HR 1.748; 95\% CI 
Table 1 The clinic-pathological characteristics of patients in various lymph node yield groups

\begin{tabular}{|c|c|c|c|c|c|}
\hline \multirow{3}{*}{ Age at surgery } & \multirow{2}{*}{$\begin{array}{l}\text { Total } \\
N=659\end{array}$} & \multirow{2}{*}{$\begin{array}{l}L N<12 \\
N=227\end{array}$} & \multirow{2}{*}{$\begin{array}{l}\text { LN12-19 } \\
N=268\end{array}$} & \multirow{2}{*}{$\begin{array}{l}L N \geq 20 \\
N=164\end{array}$} & \multirow[t]{2}{*}{$p$} \\
\hline & & & & & \\
\hline & $71.8 \pm 12.1$ & $72.1 \pm 11.46$ & $73.42 \pm 11.14$ & $68.51 \pm 13.81$ & $<0.001$ \\
\hline \multicolumn{6}{|l|}{ Gender } \\
\hline Male & $363(55.1 \%)$ & $132(58.1 \%)$ & 155(57.89\%) & $76(46.3 \%)$ & \multirow[t]{2}{*}{0.034} \\
\hline Female & $296(44.9 \%)$ & 95(41.9\%) & $113(42.2 \%)$ & 88 (53.7\%) & \\
\hline \multicolumn{6}{|l|}{ ASA } \\
\hline $1-2$ & $431(65.4 \%)$ & 144(66.1) & 166(63.6) & 121(80.1) & \multirow[t]{2}{*}{0.002} \\
\hline$\geq 3$ & 199 (30.2\%) & 74(33.9) & $95(36.4 \%)$ & $30(19.9 \%)$ & \\
\hline $\mathrm{CCl}$ & $2.47 \pm 0.8$ & $2.4 \pm 0.8$ & $2.6 \pm 0.8$ & $2.4 \pm 0.7$ & 0.105 \\
\hline Preoperative CEA & $12.5 \pm 40.6$ & $8.7 \pm 30.6$ & $13.1 \pm 39.1$ & $16.7 \pm 53.3$ & 0.245 \\
\hline \multicolumn{6}{|l|}{ Year of surgery } \\
\hline 2003-2007 & 329 (49.9\%) & 151 (66.5\%) & 110 (41.0\%) & $68(41.5 \%)$ & \multirow[t]{2}{*}{$<0.001$} \\
\hline 2008-2012 & $330(50.1 \%)$ & 76 (33.5\%) & $158(59.0 \%)$ & 96 (58.5\%) & \\
\hline \multicolumn{6}{|l|}{ Type of surgery } \\
\hline Elective & $555(84.2 \%)$ & 187 (82.4\%) & 231 (86.2\%) & 137 (83.5\%) & \multirow[t]{2}{*}{0.491} \\
\hline Emergency & $104(15.8 \%)$ & $40(17.6 \%)$ & 37 (13.8\%) & 27 (16.5\%) & \\
\hline \multicolumn{6}{|l|}{ Surgical approach } \\
\hline Laparoscopic & $304(46.1 \%)$ & 90 (39.8\%) & 137 (51.3\%) & $77(47.0 \%)$ & \multirow[t]{3}{*}{0.011} \\
\hline Open & 335 (50.8\%) & 134 (59.3\%) & $121(45.3 \%)$ & 80 (48.8\%) & \\
\hline Laparoscopic converted open & $18(2.7 \%)$ & $2(0.9 \%)$ & $9(3.4 \%)$ & $7(4.3 \%)$ & \\
\hline \multicolumn{6}{|l|}{ Site of tumour } \\
\hline Caecum & $72(10.9 \%)$ & $24(10.6 \%)$ & $31(11.6 \%)$ & $17(10.4 \%)$ & \multirow[t]{7}{*}{0.914} \\
\hline Ascending colon & $97(14.7 \%)$ & $28(12.3 \%)$ & $45(16.8 \%)$ & $24(14.6 \%)$ & \\
\hline Hepatic flexure & $63(9.6 \%)$ & 17 (7.5\%) & $27(10.1 \%)$ & 19 (11.6\%) & \\
\hline Transverse colon & $93(14.1 \%)$ & $33(14.5 \%)$ & 37 (13.8\%) & $23(14.0 \%)$ & \\
\hline Splenic flexure & $31(4.7 \%)$ & $10(4.4 \%)$ & $11(4.1 \%)$ & $10(6.1 \%)$ & \\
\hline Descending colon & $67(10.2 \%)$ & $28(12.3 \%)$ & $26(9.7 \%)$ & $13(7.9 \%)$ & \\
\hline Sigmoid colon & $236(35.8 \%)$ & 87 (38.3\%) & 91 (33.9\%) & $7(35.3 \%)$ & \\
\hline \multicolumn{6}{|l|}{ Type of resection } \\
\hline Right sided & $323(49.0 \%)$ & 99 (43.6) & $139(51.9 \%)$ & $85(51.8 \%)$ & \multirow[t]{3}{*}{0.159} \\
\hline Left sided & $306(46.4 \%)$ & $120(52.9 \%)$ & $117(43.7 \%)$ & $69(42.1 \%)$ & \\
\hline Subtotal & $30(4.6 \%)$ & $8(3.5 \%)$ & $12(4.5 \%)$ & $10(6.1 \%)$ & \\
\hline \multicolumn{6}{|l|}{ Perforation } \\
\hline Yes & $29(4.4 \%)$ & $10(4.4 \%)$ & $13(4.9 \%)$ & $6(3.7 \%)$ & \multirow[t]{2}{*}{0.842} \\
\hline No & $630(95.6 \%)$ & $217(95.6 \%)$ & 255(95.1\%) & 158(96.3\%) & \\
\hline \multicolumn{6}{|l|}{ Obstruction } \\
\hline Yes & $114(17.3 \%)$ & $37(16.4 \%)$ & 44(16.4\%) & 33 (20.2\%) & \multirow[t]{2}{*}{0.531} \\
\hline No & $543(82.4 \%)$ & 189(83.6\%) & $224(83.6 \%)$ & 130(79.8\%) & \\
\hline Tumour size & $42.1 \pm 26.6$ & $37.1 \pm 21.9$ & $42.6 \pm 27.5$ & $48.0 \pm 29.7$ & $<0.001$ \\
\hline T stage & & & & & \\
\hline $1 \& 2$ & 155 (23.6\%) & 68 (30.0\%) & $61(22.8 \%)$ & 26 (15.9\%) & 0.005 \\
\hline $3 \& 4$ & $503(76.4 \%)$ & 159 (70.0\%) & 206 (77.2\%) & 138 (84.1\%) & \\
\hline Differentiation & & & & & \\
\hline Well & $58(8.8 \%)$ & $24(11.3 \%)$ & 24 (9.2\%) & 10 (6.2\%) & 0.563 \\
\hline
\end{tabular}


Table 1 The clinic-pathological characteristics of patients in various lymph node yield groups (Continued)

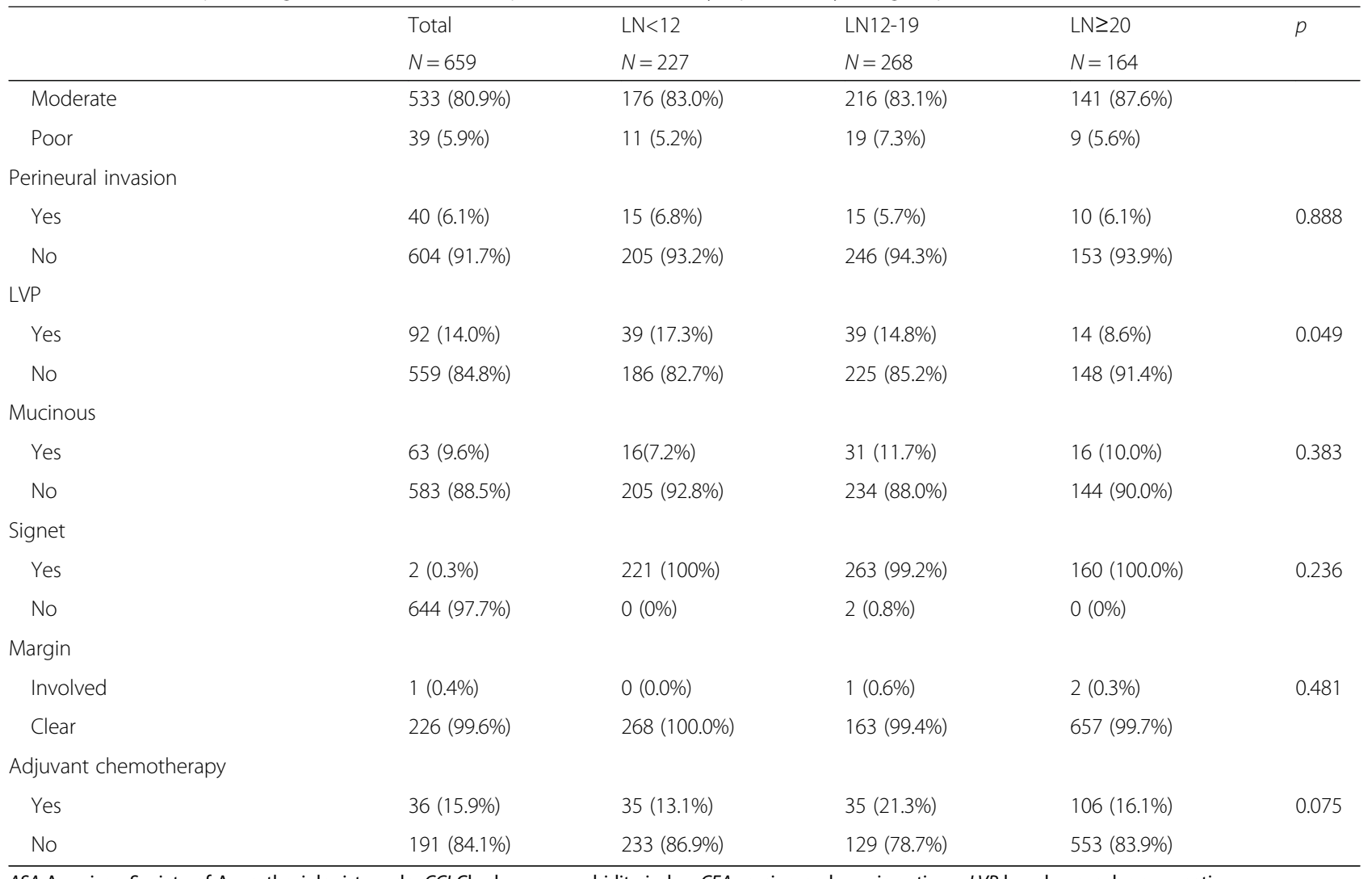

ASA American Society of Anaesthesiologist grade, CCI Charlson co-morbidity index, CEA carcino-embryonic antigen, LVP lymphovascular permeation

$1.328-2.299, p<0.001$ ), age (HR 1.059; 95\% CI 1.042$1.076, p<0.001)$ and $\mathrm{T}$ stage $\geq 3$ ( $\mathrm{HR} 1.428 ; 95 \% \mathrm{CI}$ $1.022-1.995, p=0.037$ ) (Table 4).

\section{Discussion}

Adequate lymph node yield is vital for accurate staging, determining prognosis and ascertaining the need for adjuvant treatment. The American Society of Clinical Oncology (ASCO) recommends the use of adjuvant chemotherapy in patients with stage II diseases and have a lymph node yield of less than 12 [8]. Adequate lymph node sampling was also frequently seen as an indicator of oncological clearance and cancer surgery quality $[9,10]$.

However, lymph node yield is affected by a multitude of factors. Apart from technical factors like the extent of resection, it also depends on factors that were not controllable by surgeons. Studies have shown that a higher lymph node yield was more likely seen in young age, right-sided resection, advanced $\mathrm{T}$ and $\mathrm{N}$ stage and greater tumour size
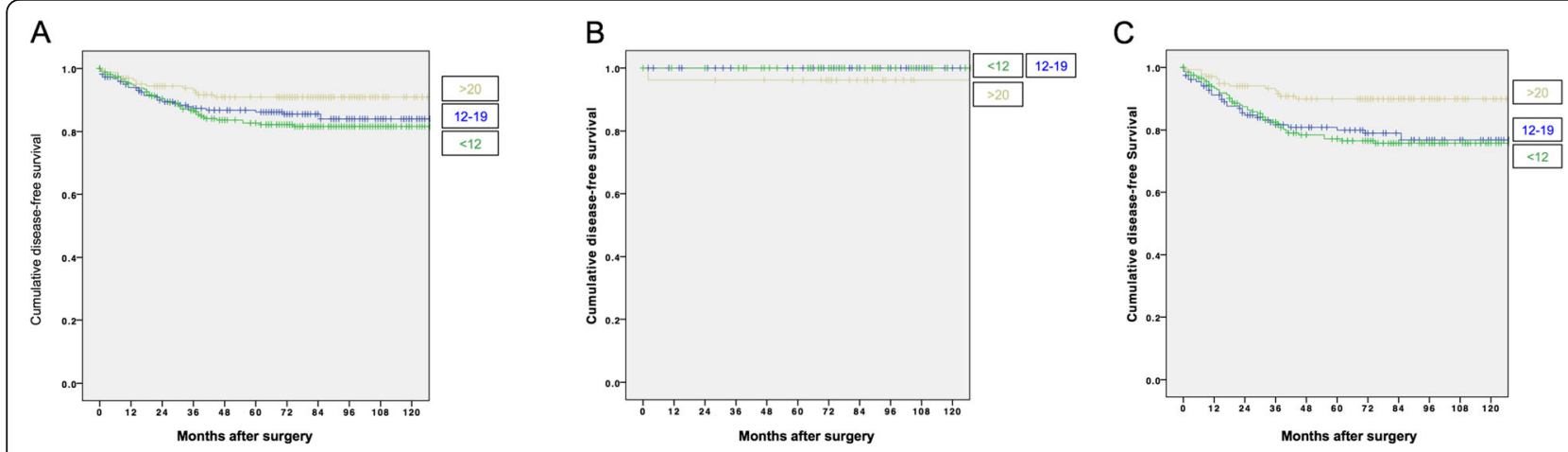

Fig. 1 Disease-free survival curves for a overall, b stage I disease and c stage II disease 
Table 2 The survival outcomes of patients in various lymph node yield group

\begin{tabular}{lllll}
\hline & \multicolumn{3}{l}{ Lymph node yield } & $p$ \\
\cline { 2 - 3 } & $<12$ & $12-19$ & $\geq 20$ & \\
\hline $\begin{array}{l}\text { Disease-free survival } \\
\text { Stage I and II }\end{array}$ & & & & 0.015 \\
$\quad$ 5 years & 86.2 & 82.7 & 91.0 & \\
10 years & 84.0 & 81.6 & 91.0 & NA \\
Stage I & & & & \\
5 years & 100 & 100 & 96.2 & \\
10 years & 100 & 100 & 96.2 & \\
Stage II & & & & \\
5 years & 80.0 & 77.2 & 90.0 & \\
10 years & 76.8 & 75.8 & 90.0 & \\
Overall survival & & & & \\
Stage I and II & & & & \\
5 years & 68.2 & 70.4 & 78.9 & \\
10 years & 44.8 & 51.2 & 57.5 & \\
Stage I & & & & \\
5 years & 83.8 & 81.4 & 88.5 & \\
10 years & 60.0 & 70.1 & 55.0 & \\
Stage II & & & & \\
5 years & 61.4 & 67.1 & & \\
10 years & 38.5 & 46.2 & & \\
\hline
\end{tabular}

[11-15]. The lymph node yield within an institution was also shown to be increasing at a rate of $2-3 \%$ per year [16].

Yet, lymph node yield was not only important for accurate staging. It was shown to correlate with survival in colon cancer patients, with those having a better survival when the lymph node yield was higher [4, 5, 17-21]. The logical way to explain this was a stage migration effect, i.e. more patients would be upstaged to stage III diseases if more lymph nodes were sampled [22]. However, this was disproved by previous studies. A Canadian population-based study showed that higher lymph node yield was not associated with an increase in the rate of node-positive disease [23]. Parsons and van Erning both found that the lymph node yield had increased considerably through the years but the proportion of stage III diseases remained similar [24, 25]. Storli compared hospitals with different surgical radicality and specimen evaluation methods. Despite an increase in the lymph node yield in centres with more aggressive resection and more dedicated pathologists, the percentage of stage III diseases was similar [26]. These showed that improved survival could not be explained by an upstaging effect.

Another way to explain this was the lymph node yield could be a representation of the underlying immunological response to cancer [27]. Advanced and bigger tumours are more likely to elicit a greater immunological response and hence render the lymph nodes easier to be found. An inherent better immunological response may be the answer as to why patients with more lymph node sampled had better survival. The association between microsatellite instability and lymph node yield has also been explored. Adequate lymph node harvest was more likely seen in tumours with microsatellite instability, with an odds ratio of 2.3 to 2.5 [28, 29]. While tumours with microsatellite instability were known to be associated with a good prognosis, whether this is the answer as to why patients with a greater lymph node yield had better survival remains to be elucidated [30-33].

Surgeons often strive to improve cancer control by adequate removal of the lymphatics draining the tumourbearing colon. Yet, current evidence did not support an overzealous approach. Excessive longitudinal resection, albeit with higher lymph node yield, has no impact on survival outcomes [34]. Also, the value of removing apical lymph nodes by central vascular ligation, as in complete mesocolic excision, is subjected to debate. The evidence was still conflicting at present [6]. The Japan Society for Cancer of the Colon and Rectum recommends apical lymph node removal for advanced disease [35]. Despite that, central vascular ligation and apical lymph node removal were not shown to have an impact on survival and this represents an area that warrants further research [36].

The term inadequate lymph node yield is often misleading. A study had shown a lower lymph node yield, e.g. nine, as adequate for staging [3]. While the importance of adequate oncological clearance should not be understated, the absolute number of lymph node harvested may just be a mere reflection of underlying body immune response. The current study showed an improved survival was associated with the lymph node yield of greater than 20. The causality between lymph node yield and survival was not proven. However, a higher lymph node yield could be seen as a prognostic marker. The survival outcomes of patients with lymph node yield less than 12 were similar to those between 12 and 19. During the study period, there was a gradual adoption of the laparoscopic approach but the principle of colon cancer resection remained unchanged. The year of diagnosis was associated with a difference in lymph node yield but did not have an impact on survival outcomes. Lymph node yield below 12 per se, after adequate resection adhering to the principles of oncological clearance and diligent pathological examination, should not be seen as a risk factor. On the other hand, a lower lymph node yield associated with inadequate surgical resection poses a risk of under-staging and should follow the recommendation of ASCO and consider adjuvant treatment. 
Table 3 The univariate and multivariate analysis of various clinic-pathological factors, using disease-free survival as the dependent variable

\begin{tabular}{|c|c|c|c|c|}
\hline & Univariate HR & $p$ & ${ }^{*}$ Multivariate $\mathrm{HR}$ & $p$ \\
\hline Age & $1.009(0.991-1.028)$ & 0.314 & & \\
\hline Male & $1.309(0.859-1.996)$ & 0.211 & & \\
\hline$A S A \geq 3$ & $1.150(0.729-1.815)$ & 0.549 & & \\
\hline Year of surgery 2003-2007 & $1.399(0.919-2.130)$ & 0.117 & & \\
\hline Preoperative CEA & 1.005 (1.002-1.009) & 0.001 & $1.004(1.000-1.008)$ & 0.038 \\
\hline $\mathrm{CCl}$ & $0.919(0.689-1.224)$ & 0.563 & & \\
\hline Obstruction & $2.403(1.530-3.773)$ & $<0.001$ & $2.061(1.128-3.767)$ & 0.019 \\
\hline Perforation & $2.971(1.436-6.145)$ & 0.003 & & \\
\hline Emergency surgery & $2.549(1.606-4.046)$ & $<0.001$ & & \\
\hline Laparoscopic approach & $0.577(0.377-0.884)$ & 0.012 & & \\
\hline Right-sided resection & $1.117(0.739-1.688)$ & 0.601 & & \\
\hline Poor differentiation & $2.902(1.612-5.223)$ & $<0.001$ & $2.263(1.058-4.843)$ & 0.035 \\
\hline Tumour size & $1.008(1.001-1.015)$ & 0.020 & & \\
\hline $\mathrm{T} 3 / 4$ & $31.426(4.378-225.571)$ & $<0.001$ & $17.216(2.367-125.235)$ & 0.005 \\
\hline LVP & $2.259(1.385-3.682)$ & 0.001 & & \\
\hline Perineural invasion & $2.713(1.477-4.983)$ & 0.001 & & \\
\hline Mucinous & $1.777(1.005-3.143)$ & 0.048 & & \\
\hline$L N$ yield $\geq 20$ & $0.510(0.289-0.903)$ & 0.021 & $0.358(0.170-0.756)$ & 0.007 \\
\hline
\end{tabular}

HR hazard ratio, ASA American Society of Anaesthesiologist grade, CCI Charlson co-morbidity index, CEA carcino-embryonic antigen, LVP lymphovascular permeation

HR > 1 signifies increased likelihood of disease recurrence

*The multivariate analysis only included significant parameters from the univariate analysis

This study was limited by its retrospective nature and therefore bias could exist between the different groups. There were differences in the clinic-pathological characteristics between the three groups. Patients in the $\mathrm{LN} \geq 20$ group were younger, had a lower ASA grade, had bigger tumours and were less likely to be operated with the open approach. Prior studies showed that bigger tumours and younger age were associated with a higher lymph node yield $[11,16]$. Surgeons in the unit followed a standardized operative approach. Nevertheless, there remained a possibility that young and fit patients with bigger tumours were treated more aggressively. Likewise, there was a possibility that patients in the $\mathrm{LN} \geq 20$ group were operated by experienced surgeons who were proficient in the laparoscopic approach. Nevertheless, none of these was predictors of DFS. ASA grade and age certainly affected the analysis of OS. By performing multivariate analysis of the DFS, the effect was minimized.

There was also a possibility that a difference in survival was not detected between the groups of lymph
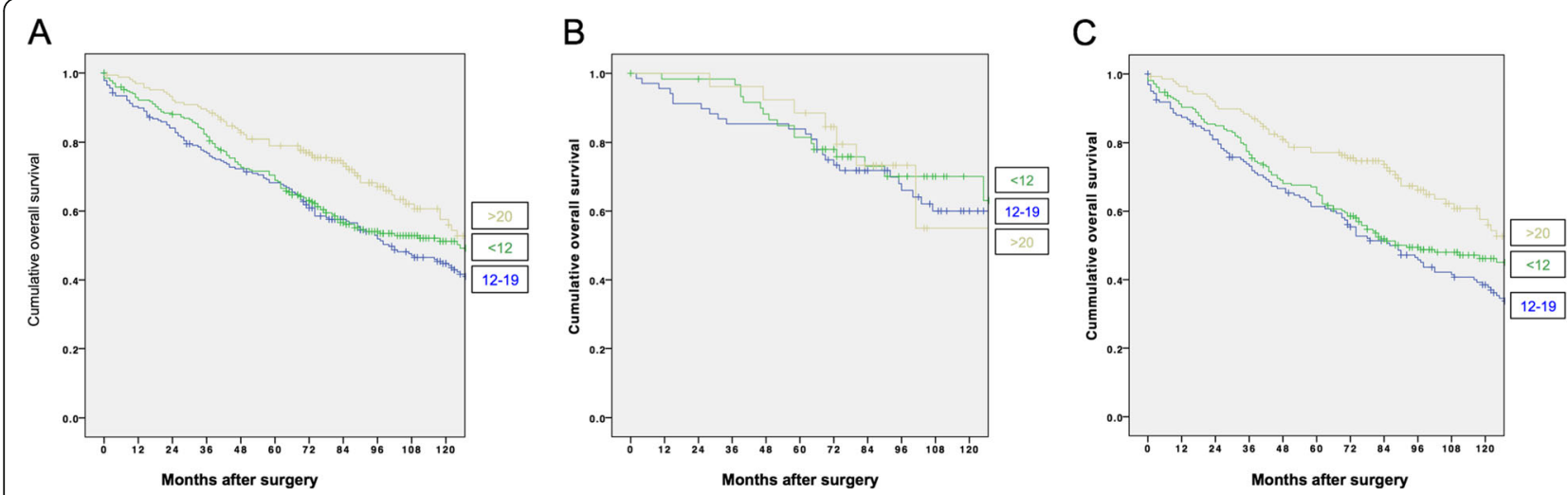

Fig. 2 Overall survival curves for a overall, b stage I disease and $\mathbf{c}$ stage II disease 
Table 4 The univariate and multivariate analysis of various clinic-pathological factors, using overall survival as the dependent variable

\begin{tabular}{llll}
\hline & Univariate HR & $p$ & *Multivariate HR \\
\hline Age & $1.053(1.041-1.066)$ & $<0.001$ & $1.059(1.042-1.076)$ \\
Male & $1.449(1.157-1.816)$ & 0.001 & $1.748(1.328-2.299)$ \\
ASA $\geq 3$ & $2.480(1.972-3.118)$ & $<0.001$ & $1.907(1.443-2.521)$ \\
Year of surgery 2003-2007 & $1.129(0.894-1.428)$ & 0.308 & \\
Preoperative CEA & $1.004(1.001-1.006)$ & 0.005 & $1.005(1.002-1.008)$ \\
CCl & $1.364(1.205-1.543)$ & $<0.001$ & \\
Obstruction & $1.482(1.133-1.938)$ & 0.004 & \\
Perforation & $2.463(1.581-3.837)$ & $<0.001$ & \\
Emergency surgery & $1.953(1.498-2.547)$ & $<0.001$ & \\
Laparoscopic approach & $0.630(0.502-0.790)$ & $<0.001$ & \\
Right-sided resection & $1.364(1.094-1.700)$ & 0.006 & \\
Poor differentiation & $1.127(0.716-1.774)$ & 0.605 & \\
Tumour size & $1.020(0.908-1.145)$ & 0.741 & \\
T3/4 & $1.738(1.291-2.340)$ & $<0.001$ & $1.428(1.022-1.995)$ \\
LVP & $1.634(1.227-2.176)$ & 0.001 & $1.580(1.110-2.250)$ \\
Perineural invasion & $1.759(1.185-2.611)$ & 0.005 & 0.037 \\
Mucinous & $1.124(0.794-1.925)$ & 0.509 & 0.011 \\
LN yield $\geq 20$ & $0.677(0.513-0.894)$ & 0.006 &
\end{tabular}

HR hazard ratio, ASA American Society of Anaesthesiologist grade, CCI Charlson co-morbidity index, CEA carcino-embryonic antigen, LVP lymphovascular permeation

HR $>1$ signifies increased likelihood of mortality

*The multivariate analysis only included significant parameters from the univariate analysis

node yield less than 12 and between 12 and 19 due to the relative small sample size. The quality of the mesocolon was not graded by surgeons or pathologists and was not analysed in this study. A better mesocolon quality may be associated with higher lymph node yield and hence served as a potential confounding factor for survival outcomes.

\section{Conclusion}

In conclusion, patients with lymph node yield greater than 20 were associated with better survival. This could be seen as a prognostic factor for better oncological outcomes. Those with lymph node yield less than 12 had similar survival outcomes as those with more than 12 but less than 20. Given adequate surgery and pathological examination, lymph node yield less than 12 should not be seen as a poor prognostic factor.

\section{Acknowledgements}

Not applicable

\section{Authors' contributions}

CCF was responsible for conception and design, analysis and interpretation of data and preparation of the manuscript. CK, JY, TYC, JT and RW were responsible for the acquisition of data and interpretation of data. WLL and $\mathrm{OL}$ were responsible for conception and design, revision and final approval of the manuscript. All authors read and approved the final manuscript.
Funding

This study did not receive funding support.

Availability of data and materials

The datasets generated and/or analysed during the current study are available from the corresponding author on request.

\section{Ethics approval}

This study was performed in accordance with the Declaration of Helsinki and approved by the Institutional Review Board of the University of Hong Kong/ Hospital Authority.

\section{Consent for publication}

Not applicable as there were no identifiable materials included in this manuscript

\section{Competing interests}

The authors declare that they have no competing interests.

\section{Author details}

${ }^{1}$ Department of Surgery, University of Hong Kong, Hong Kong, China. ${ }^{2}$ Department of Surgery, Queen Mary Hospital, Hong Kong, China.

Received: 19 September 2019 Accepted: 21 January 2020 Published online: 29 January 2020

\section{References}

1. Edge SB, Compton CC. The American Joint Committee on Cancer: the 7th edition of the AJCC cancer staging manual and the future of TNM. Ann Surg Oncol. 2010;17(6):1471-4.

2. Scott KW, Grace RH. Detection of lymph node metastases in colorectal carcinoma before and after fat clearance. Br J Surg. 1989;76(11):1165-7. 
3. Cianchi F, Palomba A, Boddi V, et al. Lymph node recovery from colorectal tumor specimens: recommendation for a minimum number of lymph nodes to be examined. World J Surg. 2002;26(3):384-9.

4. Edler D, Ohrling $K$, Hallstrom $M$, Karlberg M, Ragnhammar $P$. The number of analyzed lymph nodes - a prognostic factor in colorectal cancer. Acta Oncol. 2007:46(7):975-81.

5. Le Voyer TE, Sigurdson ER, Hanlon AL, et al. Colon cancer survival is associated with increasing number of lymph nodes analyzed: a secondary survey of intergroup trial INT-0089. J Clin Oncol. 2003;21(15):2912-9.

6. Kontovounisios C, Kinross J, Tan E, Brown G, Rasheed S, Tekkis P. Complete mesocolic excision in colorectal cancer: a systematic review. Color Dis. 2015;17(1):7-16.

7. Del Paggio JC, Peng Y, Wei $X$, et al. Population-based study to re-evaluate optimal lymph node yield in colonic cancer. Br J Surg. 2017;104(8):1087-96.

8. Benson AB 3rd, Schrag D, Somerfield MR, et al. American Society of Clinical Oncology recommendations on adjuvant chemotherapy for stage II colon cancer. J Clin Oncol. 2004;22(16):3408-19.

9. Manwaring ML, Ko CY, Fleshman JW Jr, et al. Identification of consensus-based quality end points for colorectal surgery. Dis Colon Rectum. 2012;55(3):294-301.

10. Dimofte $G$, Tarcoveanu $E$, Tarasi M, et al. Mean number of lymph nodes in colonic cancer specimen: possible quality control index for surgical performance. Chirurgia (Bucur). 2011;106(6):759-64.

11. Douaiher J, Hussain T, Langenfeld SJ. Predictors of adequate lymph node harvest during colectomy for colon cancer. Am J Surg. 2019;218(1):113-8.

12. Nedrebo BS, Soreide K, Nesbakken A, Eriksen MT, Soreide JA, Korner H. Risk factors associated with poor lymph node harvest after colon cancer surgery in a national cohort. Color Dis. 2013;15(6):e301-8.

13. Tekkis PP, Smith JJ, Heriot AG, Darzi AW, Thompson MR, Stamatakis JD. A national study on lymph node retrieval in resectional surgery for colorectal cancer. Dis Colon Rectum. 2006;49(11):1673-83.

14. Lykke J, Jess P, Roikjaer O. A high lymph node yield in colon cancer is associated with age, tumour stage, tumour sub-site and priority of surgery. Results from a prospective national cohort study. Int J Color Dis. 2016;31(7):1299-305.

15. da Costa DW, van Dekken $\mathrm{H}$, Witte $\mathrm{BI}$, van Wagensveld BA, van Tets WF, Vrouenraets BC. Lymph node yield in colon cancer: individuals can make the difference. Dig Surg. 2015;32(4):269-74.

16. Chou JF, Row D, Gonen M, Liu YH, Schrag D, Weiser MR. Clinical and pathologic factors that predict lymph node yield from surgical specimens in colorectal cancer: a population-based study. Cancer. 2010;116(11):2560-70.

17. Chang GJ, Rodriguez-Bigas MA, Skibber JM, Moyer VA. Lymph node evaluation and survival after curative resection of colon cancer: systematic review. J Natl Cancer Inst. 2007;99(6):433-41.

18. Goldstein NS. Lymph node recoveries from 2427 pT3 colorectal resection specimens spanning 45 years: recommendations for a minimum number of recovered lymph nodes based on predictive probabilities. Am J Surg Pathol. 2002;26(2):179-89.

19. Lykke J, Roikjaer $O$, Jess $P$. The relation between lymph node status and survival in stage I-III colon cancer: results from a prospective nationwide cohort study. Color Dis. 2013;15(5):559-65.

20. Swanson RS, Compton CC, Stewart AK, Bland KI. The prognosis of T3NO colon cancer is dependent on the number of lymph nodes examined. Ann Surg Oncol. 2003;10(1):65-71.

21. Norwood MG, Sutton AJ, West K, Sharpe DP, Hemingway D, Kelly MJ. Lymph node retrieval in colorectal cancer resection specimens: national standards are achievable, and low numbers are associated with reduced survival. Color Dis. 2010;12(4):304-9.

22. Feinstein AR, Sosin DM, Wells CK. The Will Rogers phenomenon. Stage migration and new diagnostic techniques as a source of misleading statistics for survival in cancer. N Engl J Med. 1985;312(25):1604-8.

23. Bui $L$, Rempel E, Reeson D, Simunovic M. Lymph node counts, rates of positive lymph nodes, and patient survival for colon cancer surgery in Ontario, Canada: a population-based study. J Surg Oncol. 2006;93(6):439-45.

24. Parsons HM, Tuttle TM, Kuntz KM, Begun JW, McGovern PM, Virnig BA. Association between lymph node evaluation for colon cancer and node positivity over the past 20 years. Jama. 2011;306(10):1089-97.

25. van Erning FN, Crolla RM, Rutten HJ, Beerepoot LV, van Krieken JH, Lemmens VE. No change in lymph node positivity rate despite increased lymph node yield and improved survival in colon cancer. Eur J Cancer. 2014;50(18):3221-9.
26. Storli K, Sondenaa K, Furnes B, et al. Improved lymph node harvest from resected colon cancer specimens did not cause upstaging from TNM stage II to III. World J Surg. 2011;35(12):2796-803.

27. Markl B, Schaller T, Kokot $Y$, et al. Lymph node size as a simple prognostic factor in node negative colon cancer and an alternative thesis to stage migration. Am J Surg. 2016;212(4):775-80.

28. Berg M, Guriby M, Nordgard $\mathrm{O}$, et al. Influence of microsatellite instability and KRAS and BRAF mutations on lymph node harvest in stage I-III colon cancers. Mol Med. 2013:19:286-93.

29. Belt EJ, te Velde EA, Krijgsman O, et al. High lymph node yield is related to microsatellite instability in colon cancer. Ann Surg Oncol. 2012;19(4):1222-30.

30. Boland CR, Goel A. Microsatellite instability in colorectal cancer Gastroenterology. 2010;138(6):2073-87 e2073.

31. Soreide $K$, Janssen EA, Soiland $H$, Korner $H$, Baak JP. Microsatellite instability in colorectal cancer. Br J Surg. 2006;93(4):395-406.

32. Dolcetti R, Viel A, Doglioni C, et al. High prevalence of activated intraepithelial cytotoxic T lymphocytes and increased neoplastic cell apoptosis in colorectal carcinomas with microsatellite instability. Am J Pathol. 1999:154(6):1805-13.

33. Samdani T, Schultheis M, Stadler Z, et al. Lymph node yield after colectomy for cancer: is absence of mismatch repair a factor? Dis Colon Rectum. 2015;58(3):288-93.

34. Hashiguchi $Y$, Hase $K$, Ueno H, Mochizuki H, Shinto E, Yamamoto J. Optimal margins and lymphadenectomy in colonic cancer surgery. Br J Surg. 2011:98(8):1171-8.

35. Hashiguchi Y, Muro K, Saito Y, et al. Japanese Society for Cancer of the Colon and Rectum (JSCCR) guidelines 2019 for the treatment of colorectal cancer. Int J Clin Oncol. 2020;25(1):1-42.

36. West NP, Kobayashi H, Takahashi K, et al. Understanding optimal colonic cancer surgery: comparison of Japanese D3 resection and European complete mesocolic excision with central vascular ligation. J Clin Oncol. 2012:30(15):1763-9.

\section{Publisher's Note}

Springer Nature remains neutral with regard to jurisdictional claims in published maps and institutional affiliations.

\section{Ready to submit your research? Choose BMC and benefit from:}

- fast, convenient online submission

- thorough peer review by experienced researchers in your field

- rapid publication on acceptance

- support for research data, including large and complex data types

- gold Open Access which fosters wider collaboration and increased citations

- maximum visibility for your research: over $100 \mathrm{M}$ website views per year

At $\mathrm{BMC}$, research is always in progress.

Learn more biomedcentral.com/submission 